\title{
Experimental study on the radial distribution of the main transition velocities in bubble columns
}

\author{
S. Nedeltchev ${ }^{1}$, U. Hampel ${ }^{1,2}$ \& M. Schubert ${ }^{1}$ \\ ${ }^{1}$ Institute of Fluid Dynamics, \\ Helmholtz-Zentrum Dresden-Rossendorf, Germany \\ ${ }^{2}$ AREVA Endowed Chair of Imaging Technologies in Energy and \\ Process Engineering, Institute of Energy Technik, \\ Dresden University of Technology, Germany
}

\begin{abstract}
The effect of the radial position on the main transition velocities in bubble columns has not been reported in the literature hitherto. In this paper, the information entropies $I E$ were extracted in a new way from local gas holdup fluctuations measured by a wire-mesh sensor at different radial positions in both small ( $0.15 \mathrm{~m}$ in ID) and large (0.4 $\mathrm{m}$ in ID) bubble columns. On the basis of well-defined local minima in the $I E$ profiles, the transition velocities $U_{\text {trans }}$ at the different radial positions were identified successfully. It was found that in the small column the first transition velocity $U_{\text {trans, } 1}$ (corresponding to the end of the gas maldistribution regime) was somewhat lower in the center of the column as compared to the wall. In the large column, the $U_{\text {trans }, 1}$ value in the center was somewhat higher than the one at the wall. The second transition velocity $U_{\text {trans, } 2}$ (corresponding to the onset of the churn-turbulent regime) in the small column was slightly higher at the core of the column. In the large column, the $U_{\text {trans, } 2}$ value was changing constantly from $U_{\mathrm{G}}=0.089 \mathrm{~m} / \mathrm{s}$ to $0.101 \mathrm{~m} / \mathrm{s}$ and vice versa. The $I E$ results showed that only at the fifth radial position in the small column and at the third and fourth radial positions in the large column there was a division of the transition regime into first and second transition sub-regimes.

Keywords: bubble columns, transition velocities, information entropies, number of crossings, local gas-holdup fluctuations, wire-mesh sensor.
\end{abstract}




\section{Introduction}

Bubble columns are used frequently in the chemical industry since they have some intrinsic advantages such as high heat and mass transfer rates, large interfacial areas, low operating and maintenance costs, lack of moving parts, simplicity of construction as well as operation versatility [1]. In spite of their simple construction, the bubble column hydrodynamics are rather complex. As the superficial gas velocity $U_{\mathrm{G}}$ increases, different flow regimes with particular structures (patterns) are being developed. The boundaries of the different flow regimes are distinguished by different transition velocities $U_{\text {trans. }}$. The reliable prediction of the $U_{\text {trans }}$ values is very important for the design and scale-up of bubble columns as well as their effective operation [2]. A clear identification of the boundaries of each hydrodynamic regime is required since the degrees of mixing, heat and mass transfer as well as conversion are quite different in the homogeneous (bubbly flow) and heterogeneous (churn-turbulent) flow regimes. A few approximate flow regime maps $[3,4]$ are available in the literature but none of them covers a wide range of industrial conditions.

In bubble columns three main flow regimes (homogeneous, transition and heterogeneous) can be distinguished. The transition velocities $U_{\text {trans }}$ depend on column diameter, sparger design, height of dispersion and physical properties of gas-liquid dispersion $[3,5]$.

The homogeneous (bubbly flow) regime prevails at low $U_{\mathrm{G}}$ values, when the gas is uniformly distributed. The bubble size distribution is narrow and essentially uniform small bubbles rise vertically. The bubble size is almost entirely dictated by the type and design of gas sparger and the physical properties of the gas-liquid system [5]. There is only little interaction between individual bubbles and bubble coalescence is negligible. The gas holdup radial profile is flat and bulk liquid circulation is practically absent [5], thus, no liquid flow macrostructure can be distinguished. In many cases, there is an imperfect (nonhomogeneous, pulsating or wobbling) gas distribution, which destabilizes the homogeneous regime and leads to an earlier transition to the heterogeneous regime. Gas maldistribution can even generate directly churn-turbulent flow conditions. When the gas is non-uniformly sparged into the column, the heterogeneous regime always takes place (irrespective of $U_{\mathrm{G}}$ ).

The change from homogeneous to heterogeneous regime is a gradual process. As the transition regime starts, there is an onset of liquid circulation that is upward in the central region and downward near the column wall. The velocity profiles become parabolic in the transition regime. As a result, a transverse gas holdup profile begins to evolve, which in turn intensifies the liquid circulation [5]. Therefore, the identification of the onset of the transition regime is very important.

The heterogeneous (churn-turbulent) regime usually occurs at $U_{\mathrm{G}}$ values greater than $0.05 \mathrm{~m} / \mathrm{s}$. Bubble clusters and large bubbles appear and thus the bubble size distribution is quite large. This flow regime is characterized by a non-uniform bubble size distribution and by the existence of gross liquid circulation. The intensity of the liquid circulation (and thus turbulence) is much 
higher. Bubble ascension trajectories are completely irregular. The coalesced large bubbles move preferentially in the center of the column and the radial gas holdup profile becomes parabolic. This leads to an intense liquid macrocirculation with ascending liquid in the column center and descending liquid near the walls. This flow regime is characterized by vigorous mixing.

\section{New method for extraction of information entropies}

In previous works $[6,7]$ the information entropies $I E$ have been extracted from photon counts and differential pressure fluctuations. In this article, they are extracted from the number of crossings of the mean of the signal. The length of the time-series $(60,000$ points of the gas holdup obtained from wire-mesh sensor, see section 3 below) was divided into 6 different segments (consisting of 10,000 points) and in each of these sections the number of crossings $N_{\mathrm{c}}$ of the mean of the signal was calculated. This parameter is important since it determines the average cycle time:

$$
\mathrm{T}_{c}=\frac{\text { length of time series (units of time) }}{\mathrm{N}_{c} / 2} .
$$

The average cycle time is defined as the average time that is needed to complete a full cycle after the first passage through the average of the signal [8].

The information entropy algorithm is based on the probability $P$ of occurrence of maximum number of crossings in a given segment $\mathrm{i}$ of the signal:

$$
P_{\mathrm{i}}=\frac{N_{\mathrm{ci}}}{\sum_{\mathrm{i}=1}^{N} N_{\mathrm{ci}}} .
$$

The information amount $I$ is a function of the probability:

$$
I_{\mathrm{i}}=-\log P_{\mathrm{i}} \text {. }
$$

The total information entropy $I E$ is a product of the probabilities $P$ and the information amounts $I$ :

$$
I E=\sum_{\mathrm{i}=1}^{N} P_{\mathrm{i}} I_{\mathrm{i}} .
$$

\section{Experimental setup and measurement technique}

The gas holdup time-series data were obtained in both a small bubble column ( $0.15 \mathrm{~m}$ in ID) and a large bubble column (0.4 $\mathrm{m}$ in ID). An air-deionized water system was used in both columns. The clear liquid height was kept constant at $2.0 \mathrm{~m}$. The small bubble column was equipped with a perforated plate distributor with a small number of hole openings (14 holes with diameter $\varnothing 4 \times 10^{-3} \mathrm{~m}$ resulting in an open area of $1 \%$ ), while the large bubble column was equipped with a perforated plate distributor with large number of hole openings (101 holes with diameter $\varnothing 4 \times 10^{-3} \mathrm{~m}$ ) in order to realize also the same open area of $1 \%$. The gas holdup was measured by conductivity wire-mesh sensors (see Figure 1) installed at a height of $1.3 \mathrm{~m}$ above the distributor plate. 


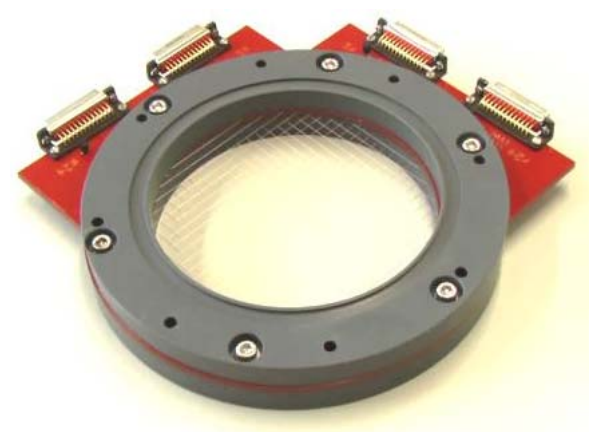

Figure 1: Design of conductivity wire-mesh sensor for the small bubble column.

The wire-mesh sensor consisted of two electrode planes (24 stainless-steel wires in the small column and 64 in the large column). The wires were $0.2 \times 10^{-3} \mathrm{~m}$ in diameter and the lateral distance between them was $6.125 \times 10^{-3} \mathrm{~m}$. The distance between the electrode planes was $4.0 \times 10^{-3} \mathrm{~m}$ and the wires from different planes ran at right angles to each other. These arrangements gave 576 crossing points in the small column and 4096 in the large column, thereof 452 and 3195 crossings inside the circular cross-sections of the small and large bubble columns, respectively.

The time series of the gas holdup consisted of 60,000 points for every $U_{G}$ value. They were obtained by averaging of the matrix data over a certain area of the sensor. It is worth noting that the raw gas holdup values were determined in percentage [\%] and they were treated in this form by the proposed analysis methods.

A new approach for flow regime identification based on the gas holdups averaged over the whole cross-section was reported in Nedeltchev et al. [9]. However, the matrix data allows to also study the effect of the radial position on the transition velocities. Thus, time-series data of gas holdup were calculated at different radial positions always averaged over an "area” of $2 \times 2$ crossing points, which corresponded to an area of $(12.25 \times 12.25) \times 10^{-3} \mathrm{~m}$. Table 1 summarizes the radial positions examined in both columns:

Table 1: Summary of the radial distances examined in both columns.

\begin{tabular}{|c|c|}
\hline \multicolumn{2}{|c|}{$D_{\mathrm{c}}=0.15 \mathrm{~m}$} \\
\hline $\begin{array}{c}\text { Index of the } \\
\text { radial position }\end{array}$ & $\begin{array}{c}\text { Dimensionless } \\
\text { radius, r/R }\end{array}$ \\
\hline P1 & 0.88 \\
\hline P2 & 0.63 \\
\hline P3 & 0.39 \\
\hline P4 & 0.14 \\
\hline P5 & 0.00 \\
\hline
\end{tabular}

\begin{tabular}{|c|c|}
\hline \multicolumn{2}{|c|}{$D_{\mathrm{c}}=0.40 \mathrm{~m}$} \\
\hline $\begin{array}{c}\text { Index of the } \\
\text { radial position }\end{array}$ & $\begin{array}{c}\text { Dimensionless } \\
\text { radius, } \mathrm{r} / \mathrm{R}\end{array}$ \\
\hline P1 & 0.92 \\
\hline P2 & 0.83 \\
\hline P3 & 0.74 \\
\hline P4 & 0.64 \\
\hline P5 & 0.00 \\
\hline
\end{tabular}


The superficial gas velocity $U_{\mathrm{G}}$ was varied from 0.01 to $0.15 \mathrm{~m} / \mathrm{s}$. At each $U_{\mathrm{G}}$, local value of the gas holdup was measured with a sampling frequency of $2000 \mathrm{~Hz}$ over a measurement period of 30 seconds.

\section{Results and discussion}

\subsection{Flow regime identification in the small bubble column}

Figure 2 shows that the information entropies (IE) extracted from the local gas holdup fluctuations recorded at radial position P1 (closest to the wall) in the small bubble column ( $0.15 \mathrm{~m}$ in ID) are capable of identifying clearly the two main transition velocities $U_{\text {trans. }}$ The end of the gas maldistribution regime occurred at $U_{\mathrm{G}}=0.045 \mathrm{~m} / \mathrm{s}$, whereas the onset of the churn-turbulent regime began at $U_{\mathrm{G}}=0.112 \mathrm{~m} / \mathrm{s}$. Both transitions were identified clearly by the well-pronounced two local minima. It is noteworthy that Nedeltchev et al. [9] (based on the gas holdup fluctuations averaged over the whole cross-section) also reached the conclusion that the second transition velocity $U_{\text {trans }}$ occurred at $U_{\mathrm{G}}=0.112 \mathrm{~m} / \mathrm{s}$.

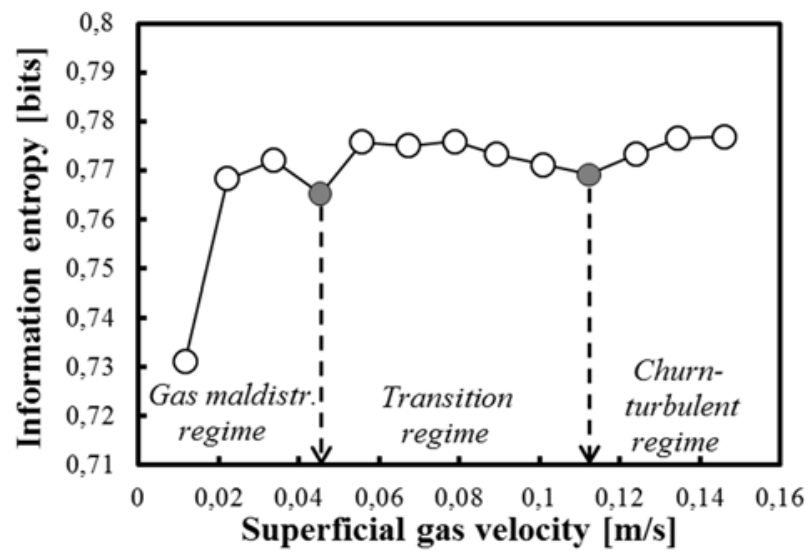

Figure 2: $I E$ values as a function of the superficial gas velocity at radial position $\mathrm{P} 1$ in the small bubble column (0.15 $\mathrm{m}$ in ID).

It was found that the $I E$ values at the radial position P2 were not capable of identifying clearly the two $U_{\text {trans }}$ values (the figure is not shown). There were multiple local maxima and minima, which hindered the clear identification of the boundaries of the various flow regimes.

Figure 3 shows the $I E$ values at radial position P3. The first local minimum occurred at $U_{\mathrm{G}}=0.034 \mathrm{~m} / \mathrm{s}$. It implies a much earlier beginning of the transition regime. The second local minimum occurred at $U_{\mathrm{G}}=0.112 \mathrm{~m} / \mathrm{s}$, which is comparable to the result in Figure 2. The small minimum at $U_{\mathrm{G}}=0.067 \mathrm{~m} / \mathrm{s}$ could be interpreted as a boundary between the first and second transition sub-regimes (Olmos et al. [10]) but it has a negligibly small practical importance 


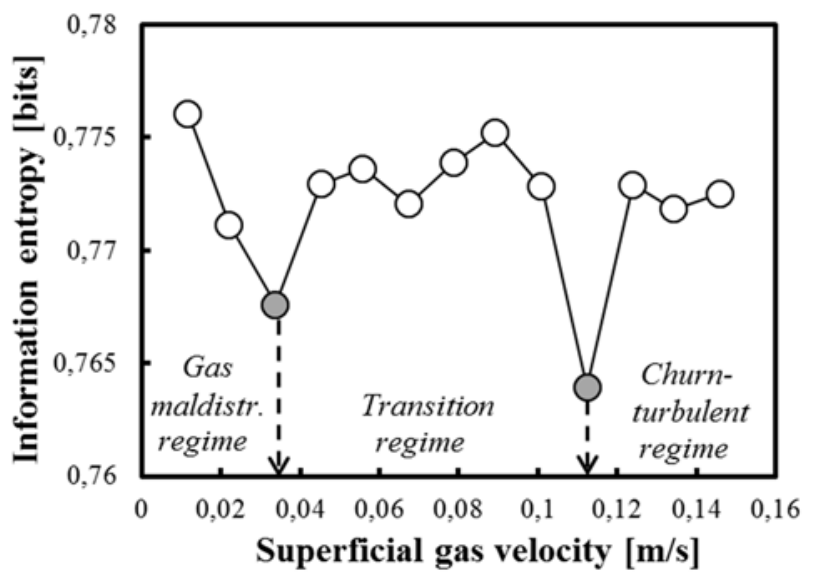

Figure 3: $I E$ values as a function of the superficial gas velocity at radial position P3 in the small bubble column (0.15 $\mathrm{m}$ in ID).

The $I E$ values at radial position $\mathrm{P} 4$ (see Figure 4) exhibited two clear local minima at $U_{\mathrm{G}}=0.034 \mathrm{~m} / \mathrm{s}$ and $0.124 \mathrm{~m} / \mathrm{s}$. A comparison with the results in Figure 3 show that only the second $U_{\text {trans }}$ value is shifted to somewhat higher value.

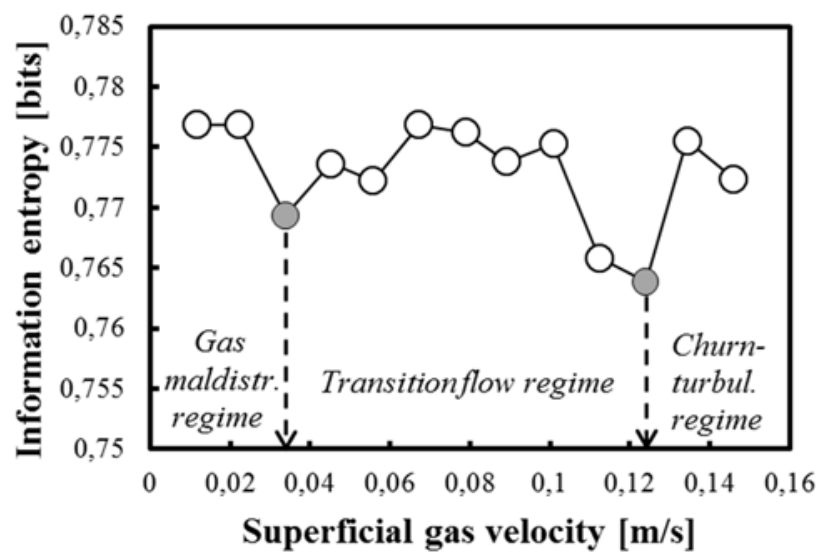

Figure 4: $I E$ values as a function of the superficial gas velocity at radial position $\mathrm{P} 4$ in the small bubble column ( $0.15 \mathrm{~m}$ in ID).

The $I E$ values at radial position P5 are shown in Figure 5. They were capable of distinguishing the end of the gas maldistribution regime at $U_{\mathrm{G}}=0.034 \mathrm{~m} / \mathrm{s}$ and the onset of the churn-turbulent regime at $U_{\mathrm{G}}=0.134 \mathrm{~m} / \mathrm{s}$. In between these two critical gas velocities there was another transition velocity at $U_{\mathrm{G}}=0.067 \mathrm{~m} / \mathrm{s}$ which distinguished the transformation of the first transition sub-regime into a second transition sub-regime. This result shows that in the core of the column the degree of liquid turbulence is much stronger. 


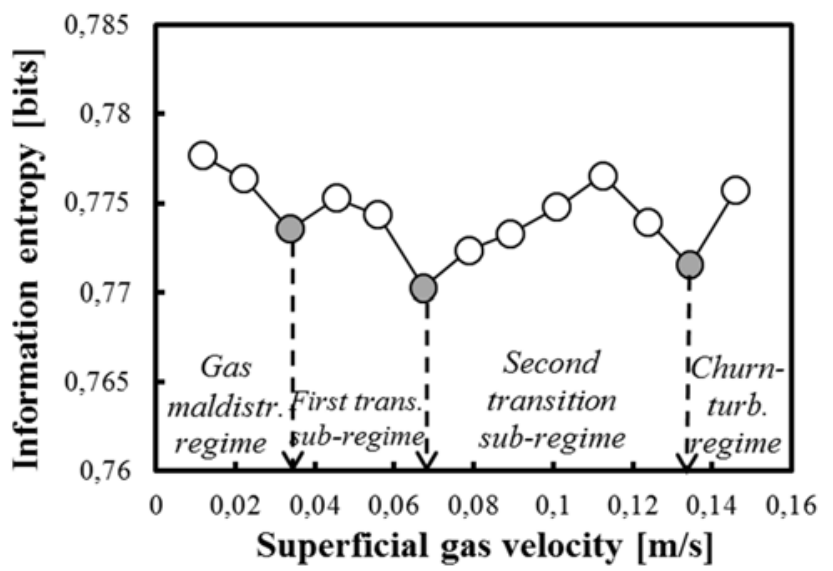

Figure 5: $I E$ values as a function of the superficial gas velocity at radial position P5 in the small bubble column (0.15 $\mathrm{m}$ in ID).

\subsection{Flow regime identification in the large bubble column}

Figure 6 shows that at radial position P1 in the large bubble column two transition velocities can be identified. The gas maldistribution regime ends at $U_{\mathrm{G}}=0.034 \mathrm{~m} / \mathrm{s}$, whereas the churn-turbulent regime begins at $U_{\mathrm{G}}=0.089 \mathrm{~m} / \mathrm{s}$. As compared to the results in the small bubble column (see Figure 2), the first $U_{\text {trans }}$ value occurred at a somewhat lower $U_{\mathrm{G}}$ value in the large column, whereas the second $U_{\text {trans }}$ value occurred at much lower $U_{\mathrm{G}}$ value in the large column.

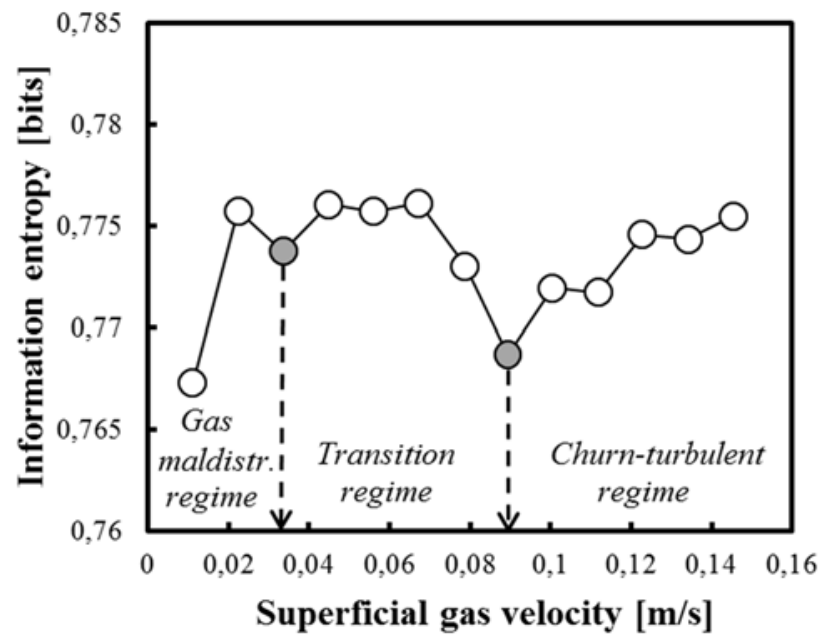

Figure 6: $I E$ values as a function of the superficial gas velocity at radial position $\mathrm{P} 1$ in the large bubble column (0.4 $\mathrm{m}$ in ID). 
Figure 7 shows that the $I E$ values at radial position P2 are also capable of identifying the two main transition velocities. At $U_{\mathrm{G}}=0.023 \mathrm{~m} / \mathrm{s}$ begins the transition flow regime. A well-pronounced local minimum occurred at $U_{\mathrm{G}}=0.101 \mathrm{~m} / \mathrm{s}$ which distinguished the onset of the churn-turbulent regime.

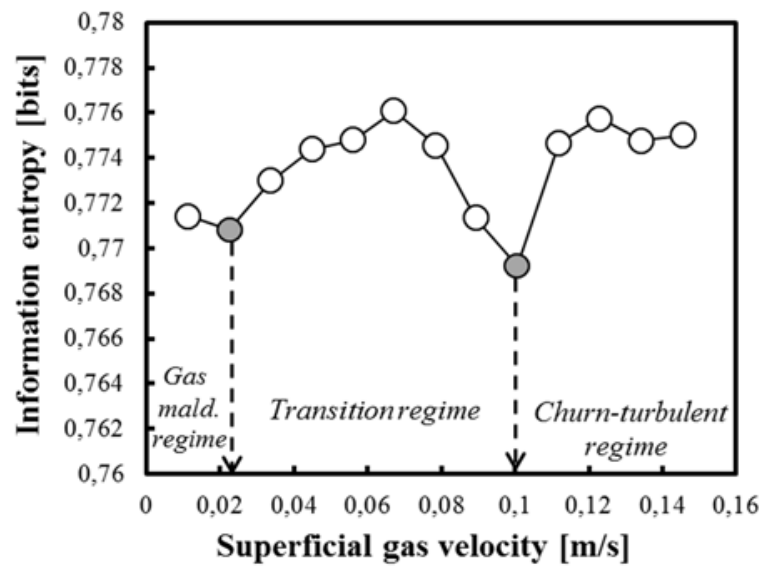

Figure 7: $I E$ values as a function of the superficial gas velocity at radial position $\mathrm{P} 2$ in the large bubble column (0.4 $\mathrm{m}$ in ID).

A comparison between the results for radial positions P1 and P2 in Figures 6 and 7, respectively, reveals that towards the core of the column the first $U_{\text {trans }}$ value shifts to somewhat lower superficial gas velocity $U_{\mathrm{G}}$, whereas the second $U_{\text {trans }}$ value shifts to somewhat higher $U_{\mathrm{G}}$ value.

The $I E$ profile at radial position P3 (see Figure 8) shows that four transition velocities are distinguishable. The gas maldistribution regime ends at $U_{\mathrm{G}}=0.034 \mathrm{~m} / \mathrm{s}$. The first transition sub-regime transforms itself into a second

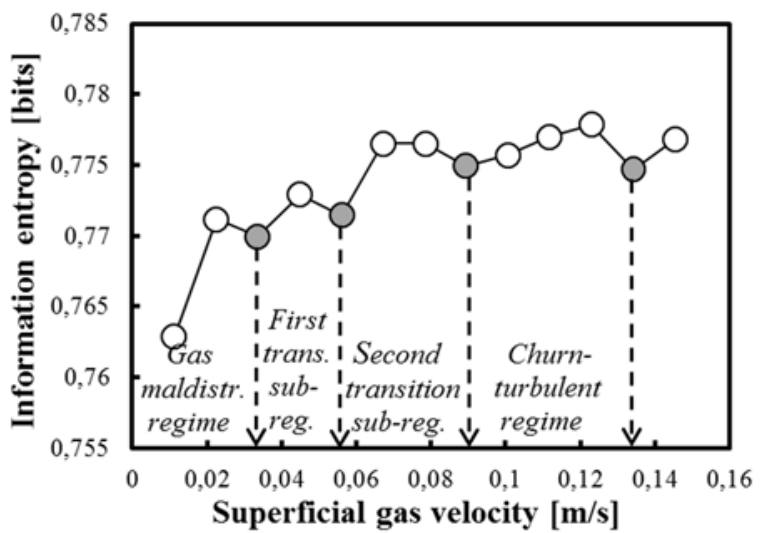

Figure 8: $I E$ values as a function of the superficial gas velocity at radial position P3 in the large bubble column (0.4 $\mathrm{m}$ in ID). 
transition sub-regime at $U_{\mathrm{G}}=0.056 \mathrm{~m} / \mathrm{s}$. The churn-turbulent regime varies in the range from 0.089 to $0.134 \mathrm{~m} / \mathrm{s}$. The existence of four transition velocities is an indication of an increased degree of liquid turbulence at radial position P3.

Four $U_{\text {trans }}$ values were also distinguished at radial position P4 (see Figure 9) in the large bubble column. The gas maldistribution regime ended at $U_{\mathrm{G}}=0.034 \mathrm{~m} / \mathrm{s}$, whereas the churn-turbulent regime began at $U_{\mathrm{G}}=0.101 \mathrm{~m} / \mathrm{s}$ (distinguished by a very clear local minimum). The transformation of the first transition sub-regime into a second one occurred at $U_{\mathrm{G}}=0.067 \mathrm{~m} / \mathrm{s}$. Apparently, as the radial position gets closer to the center of the column, the degree of turbulence increases and this affects the $I E$ profiles (which identify four $U_{\text {trans }}$ values).

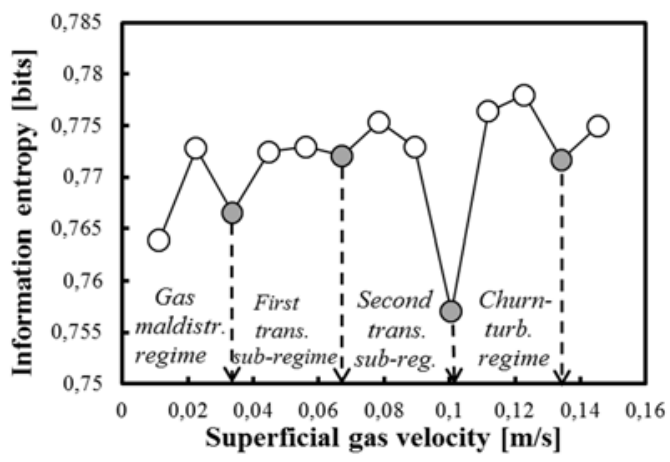

Figure 9: $I E$ values as a function of the superficial gas velocity at radial position P4 in the large bubble column (0.4 $\mathrm{m}$ in ID).

Figure 10 shows that in the center of the large column two $U_{\text {trans }}$ values $(0.045$ and $0.089 \mathrm{~m} / \mathrm{s}$ ) are clearly distinguishable on the basis of two well-pronounced minima. Due to the increased turbulence in the center of the column the $I E$ profile exhibits some fluctuations. As compared to the previous four positions, the onset of the transition regime is somewhat delayed which is due to the worse gas distribution in the core of the column.

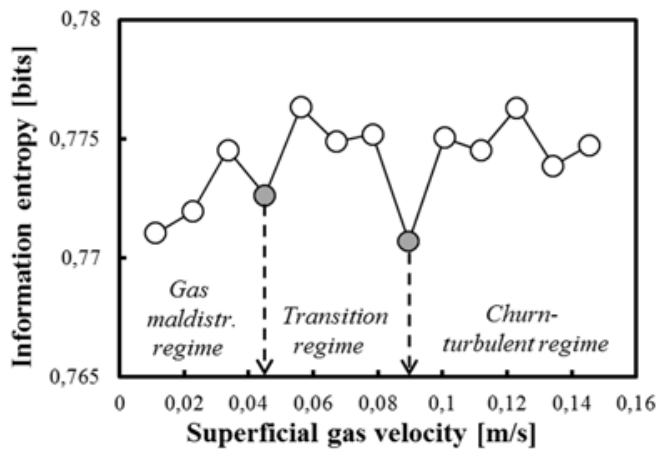

Figure 10: $I E$ values as a function of the superficial gas velocity at radial position $\mathrm{P} 5$ in the large bubble column (0.4 $\mathrm{m}$ in ID). 


\subsection{Summary of the results}

Table 2 summarizes the two main transition velocities (end of gas maldistribution regime $U_{\text {trans,1 }}$ and onset of churn-turbulent regime $U_{\text {trans,2) }}$ identified at each radial position (based on $I E$ results) in both small $(0.15 \mathrm{~m}$ in ID) and large (0.4 $\mathrm{m}$ in ID) bubble columns.

Table 2: Summary of the main transition velocities based on $I E$ results.

\begin{tabular}{|c|c|c|c|c|}
\hline $\begin{array}{c}\text { Radial } \\
\text { position }\end{array}$ & $\begin{array}{c}r / R \\
{[-]}\end{array}$ & $\begin{array}{c}D_{\mathrm{c}} \\
{[\mathrm{m}]}\end{array}$ & $\begin{array}{c}U_{\text {trans,1 }} \\
{[\mathrm{m} / \mathrm{s}]}\end{array}$ & $\begin{array}{c}U_{\text {trans,2 }} \\
{[\mathrm{m} / \mathrm{s}]}\end{array}$ \\
\hline P1 & 0.88 & 0.15 & 0.045 & 0.112 \\
\hline P2 & 0.63 & 0.15 & Not identifiable & Not identifiable \\
\hline P3 & 0.39 & 0.15 & 0.034 & 0.112 \\
\hline P4 & 0.14 & 0.15 & 0.034 & 0.112 \\
\hline P5 & 0.00 & 0.15 & 0.034 & 0.134 \\
\hline P1 & 0.92 & 0.40 & 0.034 & 0.089 \\
\hline P2 & 0.83 & 0.40 & 0.023 & 0.101 \\
\hline P3 & 0.74 & 0.40 & 0.034 & 0.089 \\
\hline P4 & 0.64 & 0.40 & 0.034 & 0.101 \\
\hline P5 & 0.00 & 0.40 & 0.045 & 0.089 \\
\hline
\end{tabular}

It can be concluded that in both columns the $U_{\text {trans, } 1}$ value at most of the radial positions occurred at $0.034 \mathrm{~m} / \mathrm{s}$. This value is very close to the theoretical $U_{\text {trans }}$ prediction $(0.029 \mathrm{~m} / \mathrm{s})$ for an air-water system [11]. At radial positions P1 in the small column and P5 in the large column, however, the $U_{\text {trans, } 1}$ value occurred at $U_{\mathrm{G}}=0.045 \mathrm{~m} / \mathrm{s}$. At radial position $\mathrm{P} 2$ in the large column $U_{\text {trans, } 1}$ value was lower.

In the small column, the $U_{\text {trans,2 }}$ value in most of the radial positions was identified at $0.112 \mathrm{~m} / \mathrm{s}$. Only at the center of the column it was somewhat higher. In the large column, the $U_{\text {trans,2 }}$ value changed constantly from $0.089 \mathrm{~m} / \mathrm{s}$ to $0.101 \mathrm{~m} / \mathrm{s}$ and vice versa.

\section{Conclusion}

In order to study the radial dependence of the transition velocities, the information entropies $I E$ were extracted in a new way from the local gas holdup fluctuations measured by a wire-mesh sensor in two bubble columns ( 0.15 and $0.4 \mathrm{~m}$ in ID). The air-deionized water system was always used. It was found that in the small bubble column the first transition velocity $U_{\text {trans, } 1}$ was somewhat lower in the center of the column as compared to the wall. However, in the large column, the $U_{\text {trans, } 1}$ value in the center was slightly higher than the one at the wall. The second transition velocity $U_{\text {trans,2 }}$ in the small column was slightly higher at the core of the column. In the large column, the $U_{\text {trans,2 }}$ value was changing constantly from $U_{\mathrm{G}}=0.089 \mathrm{~m} / \mathrm{s}$ to $U_{\mathrm{G}}=0.101 \mathrm{~m} / \mathrm{s}$ and vice versa. 
The $I E$ results showed that only at radial position $\mathrm{P} 5$ in the small column and at radial positions P3 and P4 in the large column there was a division of the transition regime into both first and second transition sub-regimes.

\section{Nomenclature}

$D_{\mathrm{c}}$ - column diameter, $\mathrm{m}$

$I-$ information amount, bits

$I E$ - information entropy, bits

$N$ - number of signal segments

$N_{\mathrm{c}}$ - number of crossings

$P$ - probability of highest number of crossings in a given segment of the signal

$r / R$ - dimensionless radius

$T_{\mathrm{c}}$ - average cycle time, $\mathrm{s}$

$U_{\mathrm{G}}$ - superficial gas velocity, $\mathrm{m} / \mathrm{s}$

$U_{\text {trans }}-$ transition gas velocity, $\mathrm{m} / \mathrm{s}$

$U_{\text {trans, } 1}$ - first transition velocity (onset of transition flow regime), $\mathrm{m} / \mathrm{s}$

$U_{\text {trans,2 }}$ - second transition velocity (onset of churn-turbulent regime), $\mathrm{m} / \mathrm{s}$

\section{Acknowledgements}

Dr. Stoyan Nedeltchev is grateful to the European Commission for providing him with a Marie Curie Outgoing International Fellowship ( $7^{\text {th }}$ Framework Programme, Grant Agreement No. 221832, 2010-2013). Dr. Markus Schubert gratefully acknowledges the financial support of the European Research Council (ERC Starting Grant, Grant Agreement No. 307360). The financial support (No. ERC-0010) of the Helmholtz Association of German Research Centres within the frame of the Initiative and Networking Fund is also acknowledged.

\section{References}

[1] Deckwer, W.-D. \& Schumpe, A., Improved tools for bubble column reactor design and scale-up. Chem. Eng. Sci., 48, pp. 889-911, 1993.

[2] Simmonet, M., Gentric, C., Olmos, E. \& Midoux, N., CFD simulation of the flow field in a bubble column reactor: importance of the drag flow formulation to describe regime transitions. Chem. Eng. Process., 47, pp. 1726-1737, 2008.

[3] Shah, Y. T., Kelkar, B. G., Godbole, S. P. \& Deckwer, W.-D., Design parameters estimation for bubble column reactors. AIChE J., 28, pp. 353379, 1982.

[4] Zhang, J.-P., Grace, J. R., Epstein, N. \& Lim, K. S., Flow regime identification in gas-liquid flow and three-phase fluidized beds. Chem. Eng. Sci., 52, pp. 3979-3992, 1997. 
[5] Thorat, B. N. \& Joshi, J. B., Regime transition in bubble columns: experimental and predictions. Exp. Thermal Fluid Sci., 28, pp. 423-430, 2004.

[6] Nedeltchev, S., Shaikh A. \& Al-Dahhan, M., Flow regime identification in a bubble column via nuclear gauge densitometry and chaos analysis. Chem. Eng. Tech., 34, pp. 225-233, 2011.

[7] Nedeltchev, S. \& Shaikh, A., A new method for identification of the main transition velocities in multiphase reactors based on information entropy theory. Chem. Eng. Sci., 100, pp. 2-14, 2013.

[8] Schouten, J. C., Takens, F. \& Van den Bleek, C. M., Estimation of the dimension of a noisy attractor. Phys. Rev. E Stat. Phys. Plasmas Fluids Relat. Interdisciplin. Top., 50, pp. 1851-1861, 1994.

[9] Nedeltchev, S., Donath, Th., Rabha, S., Hampel, U. \& Schubert, M., New evidence for the mixing length concept in a narrow bubble column operated in the transition regime. J. Chem. Eng. Japan, 47, pp. 722-729, 2014.

[10] Olmos, E., Gentric, C., Poncin, S. \& Midoux, N., Description of flow regime transitions in bubble columns via laser Doppler anemometry signals processing. Chem. Eng. Sci., 58, pp. 1731-1742, 2003.

[11] Reilly, I. G., Scott, D. S., Debruijn, T. J. W. \& MacIntyre, D., The role of gas phase momentum in determining gas holdup and hydrodynamic flow regimes in bubble column operations. Can. J. Chem. Eng., 72, pp. 3-12, 1994. 